\title{
Esporte, experiência e conhecimento: um diálogo possível na educação física
}

Sport, experience and knowledge: a possible dialogue in physical education

Deporte, experiencia y conocimiento: un diálogo posible en la educación física

\author{
Paulo Carlan ${ }^{\mathrm{I}}$, Daniel Bardini Dürks ${ }^{\mathrm{II}}$
}

\begin{abstract}
Resumo
Este artigo propõe-se a refletir a relação entre esporte na contemporaneidade e experiência estética como uma possibilidade de conhecimento. O esporte, por muito tempo, tem sido concebido a partir das ciências da natureza; compreensão essa que tem uma extensa tradição na Educação Física, que, de certa perspectiva, se afasta de um "olhar" das Ciências Humanas e Sociais. Reconhecer que o esporte pode ser compreendido a partir da experiência estética, conferindo ao corpo outro status no processo de conhecimento da realidade, não negando a dimensão conceitual, mas tomando-o, enquanto linguagem, sob uma perspectiva fenomenológica-hermenêutica, é o nosso propósito.
\end{abstract}

Palavras-chave: Esportes; Estética; Educação Física

\begin{abstract}
This article proposes to reflect the relationship sport in contemporary times and the aesthetic experience as a possibility of knowledge. Sport, for a long time, has been designed from the natural sciences, understanding that that has an extensive tradition in physical education, which in some perspective moves away from a "look" of the Humanities and Social Sciences. Recognizing that sport can be understood from aesthetic experience, giving the body another status in the process of knowing reality, not denying the conceptual dimension, but taking it while a language phenomenological-hermeneutic perspective, it is our purpose.
\end{abstract}

Keywords: Sports; Esthetics; Physical Education

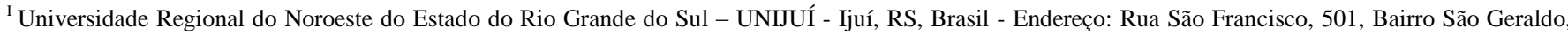
Ijuí, RS, Brasi,1 CEP: 98700-000, caixa postal: 560 - e-mail: carlan@unijui.edu.br

II Universidade Federal de Santa Maria - UFSM - Santa Maria, RS, Brasil- e-mail: daniel.durks@ yahoo.com.br
} 


\section{Resúmen}

Este artículo se propone reflejar sobre la relación entre deporte en la contemporaneidad y la experiencia estética como posibilidad de conocimiento. El deporte, durante mucho tiempo, ha sido diseñado desde las ciencias naturales, entendimiento que tiene una amplia tradición en educación física, que en cierta perspectiva, se aleja de una "mirada" de las Humanidades y Ciencias Sociales. Reconocer que el deporte puede ser entendido desde la experiencia estética, dando al cuerpo otro estatus en el proceso de conocimiento de la realidad, sin desconsiderar la dimensión conceptual, pero tomarlo como lenguaje, bajo una perspectiva fenomenológico-hermenéutico es nuestro propósito.

Palavras clave: Deportes; Estética; Educación Física

\section{Introdução}

Na Filosofia costuma-se ressaltar que o óbvio é aquilo sobre o qual paramos de pensar. Nesse sentido, temos de promover a reflexão radical (que vai às raízes) e, portanto, nunca aceitarmos como óbvia qualquer questão; afinal, as respostas humanas são sempre proposições de sentido carentes de justificação.

Nessa perspectiva, entendemos que o esporte, enquanto fenômeno sociocultural, por sua complexidade, contradição e abrangência, nos convoca a pensar a respeito, e a aprender sobre esse pensar. O estudo em relação aos diferentes elementos pertencentes ao universo esportivo não é algo inédito; pelo contrário, já foi e tem sido amplamente abordado, investigado, pesquisado e criticado, principalmente nos anos 80 do século 20. Todavia, nem por isso se entende que o binômio esporte e Educação Física esteja esgotado ou com sua validade vencida, e que não se possa fazer uma (re)-leitura de sua função social, educativa e produtora de conhecimentos, pois se compreende que o conhecimento e os saberes a respeito do esporte são decorrentes da produção humana e, por isso, devem ser descontruídos e reconstruídos à luz da ciência.

O filósofo Merleau-Ponty (1989) questionou o paradigma da ciência moderna que reduz a complexidade da relação sujeito-objeto, desconsiderando que o corpo tem outras formas de apreensão do conhecimento. Isto é, o evento de conhecer não pode ser redutível unicamente no sentido do pensamento da res cogitans (consciência/sujeito transcendental), mas, também, a partir do conceito de experiência estética, elegendo ao corpo outro status no processo de conhecimento da realidade.

O século 20 promoveu mudanças significativas no que concerne à formação humana e à formação educativa. As ciências da natureza ganharam um status de verdade absoluta, incontestável, e de legitimação nos processos de formação educativa. Compreende-se que a ciência da natureza é insuficiente para dizer tudo do que é o humano e dos sentidos e significados que este vivencia corporalmente. O paradigma de conhecimento da ciência da natureza repercutiu na sociedade contemporânea, o que tem gerado um debate em muitas instâncias e comunidades científicas, situação que Silva (2016, p. 22) denomina de um estado de crise e perplexidade da sociedade contemporânea. 
A Educação Física escolar tem tratado o conhecimento pedagógico da área a partir de duas dimensões: o saber fazer (corporal) e um saber (crítico) sobre esse fazer. Essa perspectiva de abordagem potencializou a contextualização e a historicização dos conhecimentos da Educação Física na escola. Isso desencadeou uma discussão epistemológica sobre a relação entre o conhecimento não discursivo e o conhecimento discursivo. Para além dessa relação (saber fazer e compreender/explicar o que se faz corporalmente), a experiência estética do agir humano no âmbito escolar não tem recebido uma maior dedicação de estudos e pesquisas.

Compreendemos que um dos principais eixos temáticos da Educação Física é o esporte. Da mesma forma, reconhecemos o esporte como uma prática social, muito presente na atualidade e profundamente influenciadora na formação das subjetividades. No movimento de seu avanço científico, o esporte acabou incorporando, em suas diferentes formas de manifestação, o paradigma da racionalidade instrumental, o que acabou o reduzindoo/destituindo-o à sua compreensão enquanto um fenômeno sociocultural e histórico-social (BRACHT, 2003).

Nas décadas de 70 e 80 do século 20, no Brasil, houve uma aproximação dos estudos na área da Educação Física com as Ciências Humanas e Sociais, e, nessa aproximação, a busca de um novo paradigma epistemológico para a área (BRACHT, 2003). Segundo Lima, (1999 apud BRACHT, 2012), houve um deslocamento do debate epistemológico no campo da Educação Física brasileira e argumentou-se que havia evidências de que ela estaria transitando da crítica epistemológica para a crítica estética, e que as preocupações com o corpo, sobretudo de ordem ética e estética, se constituíam no grande tema da Educação Física.

Portanto, a Educação Física vai se aproximar de um novo paradigma epistemológico apoiado pelas Ciências Humanas e Sociais para "tratar" das diferentes linguagens da cultura corporal de movimento, entre elas o esporte. Um viés teórico que tem norteado os estudos e pesquisas na área da Educação Física, tem sido a filosofia (hermenêutica-fenomenologia), tendo como foco a crítica estética. Esta perspectiva teórica vai autorizar a compreensão do fenômeno esporte como uma possibilidade do movimento corporal vinculado intimamente à subjetividade humana, que se define, no limite, pelo prazer que proporciona, pelas sensações ou pelos sentimentos que suscita em nós.

Neste diálogo da Educação Física com o aporte epistemológico das Ciências Humanas, novas formas de pensar os elementos pedagógicos do esporte são discutidas. O fenômeno esporte cresceu em importância social, política e econômica, e democratizou-se num conjunto de manifestações e sentidos mais plural: o lazer, a educação, o rendimento, a reabilitação, a qualidade de vida, a promoção da saúde, a educação inclusiva e, fundamentalmente, como uma possibilidade de apropriação cultural. Ou seja, além do estudo dos elementos ligados a lógica interna de cada prática esportiva, o estudo crítico dos aspectos sociais, culturais, políticos e epistemológicos são tensionados e necessitam de tematização constante frente ao movimento sócio-histórico.

A partir deste entendimento, este artigo tem como objetivo potencializar uma reflexão acerca da relação entre conhecimento e experiência estética na Educação Física escolar e os desdobramentos pedagógicos para pensar o fenômeno esporte. Para tanto, acenamos para a possibilidade de superar o trato do conhecimento na área da 
Educação Física pelo viés do paradigma da racionalidade instrumental, percebendo, na linguagem, uma via legítima de apropriação do conhecimento.

\section{0 esporte na sociedade e a sociedade no esporte}

O esporte faz parte da sociedade contemporânea, tanto quanto a sociedade contemporânea faz parte do esporte. É impossível compreendermos uma atividade sem tomar como referência à totalidade na qual está inserida. Por mais que estamos vivendo numa sociedade de especialização e de fragmentação (seja do conhecimento ou dos modos de intervenção), Esporte e Sociedade são duas dimensões que estão interligadas, poderíamos afirmar, como "duas faces de uma mesma moeda".

O esporte é uma das práticas corporais de maior representação na sociedade contemporânea. A pergunta que emerge dessa constatação é: Por que o esporte vende tanto? Se vende, é porque alguém está o consumindo, como praticante, como expectador, como gestor, como representante da mídia, como mercado produtor, como produtor de conhecimento. Isso significa que, de alguma forma, o fenômeno esporte ocupa na sociedade contemporânea, e, por consequência, nos sujeitos, um lugar simbólico significativo.

Segundo DaMatta (1982, p. 23), a conexão Esporte e Sociedade não é de estratificação, mas constitui “[...] relações expressivas, dramáticas, em que o começo e o fim se rebatem um no outro". A sociedade, segundo o autor, revela-se tanto pelo trabalho quanto pelo esporte, religião, rituais e a política. Cada uma dessas esferas é uma espécie de "filtro", pelo qual a ordem social se faz e se refaz, inverte-se e reafirma-se, num jogo básico para a sua própria percepção enquanto uma totalidade significativa. O esporte, como uma prática social, portanto, nos permite também descobrir a nossa "alma" e o nosso "coração" de modo positivo, como uma coletividade ou individualmente que pode, sabe e faz muito bem as coisas.

Não se trata de uma visão romântica a respeito do esporte e das implicações que se atravessam em sua efetivação (como a esfera política, a economia, o mercado, a mídia). Reconhecemos o esporte como um sistema que tem suas regras, objetos, cenários, personagens, tempo e espaço. No entanto, buscamos refletir, neste texto, que há espaço para compreendermos o esporte na sociedade contemporânea como uma produção humana, e que este está na sociedade tanto quanto a sociedade está nele. Ambos se expressam mutuamente e suas relações são muito complexas e ultrapassam a visão instrumental da racionalidade.

Para DaMatta (1982), o esporte, na sua diversidade e na sua complexidade, é uma forma de abertura para a experiência e é garantido pelo viés de uma prática social democrática, diferentemente das classificações rotineiras, quando as pessoas são definidas por meio de suas relações (família, trabalho, título, poder econômico). Aqui o autor vai destacar o conceito de permanência, quando é possível distinguir grupos mais ou menos articulados de enunciados ideológicos ligados ao esporte que corroboram representações vigentes na sociedade, e que buscam interpretar e justificar a manutenção (a reprodução) desta. 
Ainda na leitura de DaMatta (1982, p. 29), o binômio Sociedade e Esporte nos permite mostrar que o esporte é um objeto social complexo e que pode ser socialmente apropriado de vários modos. Com efeito, pode ser compreendido a partir de diferentes perspectivas teóricas, filosóficas, sociológicas, antropológicas, educacionais, bem como à "luz da ciência da natureza".

A sociedade contemporânea tem sido caracterizada por um conjunto de comportamentos, sentidos e significados, que tem produzido implicações na constituição dos sujeitos e na identidade intrasubjetiva e intersubjetiva. Destacamos, como uma das características dessa sociedade, a ausência de valores, ou, se quiser, da emergência de outros valores. Esse tempo e espaço contemporâneo, que muitos designam de pós-moderno, também tem nos negado a oportunidade da experiência estética, pois vivemos um período de "pobreza da experiência estética" (BAUMAN, 2007).

Bauman (2001) tem caracterizado a sociedade contemporânea como uma sociedade líquido-moderna. Um mundo que tem como centralidade o individual e não o indivíduo, em que a premissa principal é o permanente consumo de sensações facilmente descartáveis (BAUMAN, 2007). Neste contexto, para o autor, os valores propagados são voláteis, descuidam do futuro, são egoístas e descartáveis. As categorias do "tempo presente" e da "velocidade" são centrais na sociedade líquida-moderna. A experiência, aqui, é viver o presente sem se preocupar com as possíveis implicações futuras; o que importa é a velocidade; a sensibilidade e os valores morais já não são questões emergenciais para os indivíduos.

Neste universo volátil e que incita os indivíduos ao consumo e descarte permanente de todas as experiências vividas, compreendemos que a Educação Física possui um compromisso social em tematizar o esporte em uma outra perspectiva. Apesar de, a grosso modo, a lógica esportiva ser vinculada a competição e a técnica, a Educação Física pode contribuir para os sujeitos compreenderem o esporte como uma forma de linguagem, intimamente ligada a experienciação do se-movimentar.

Esse se-movimentar é constituído de elementos únicos pertencentes a cada sujeito que, ao ser vivido, auxilia para o conhecimento de sua própria corporeidade e sensibilidade, compondo elementos para uma experiência estética através do movimento. Essa relação do esporte enquanto uma linguagem e que se constitui como aporte para a experiência estética é o tema do próximo tópico.

\section{Esporte e experiência estética}

A relação esporte e experiência estética está intimamente articulada à subjetividade humana. Baumgarten (1993 apud MARASCA, 2008, p. 177), utiliza o termo Estética para designar "a ciência que trata do belo". Assim como existe uma ciência - a Lógica - para conhecer as coisas inteligíveis (noéta), deve haver uma ciência que permita conhecer as "coisas sensíveis" (aisthéta). Dessa forma, estão instituídas as condições para o surgimento da Estética, segundo a autora, como "ciência do conhecimento sensitivo". 
Nesse sentido, entende-se que a hermenêutica pode auxiliar a interpretar/compreender o esporte como linguagem e a sua relação com a noção de experiência estética. Destaca-se, conforme Gadamer (2008), que a linguagem não pode ser vista somente como linguagem de palavras, mas como forma de comunicação. A linguagem significa, no sentido mais amplo, toda a forma de comunicação, não somente a fala, mas também o movimento corporal (gesticular), o qual faz parte das relações linguísticas das pessoas.

Não podemos, portanto, reduzir que a forma de apreensão do conhecimento na área da Educação Física e na particularidade da prática do esporte, deve estar somente articulada ao paradigma da racionalidade instrumental. É possível perceber que a linguagem/movimento humano é uma perspectiva legítima de apreensão do conhecimento e de relação com o mundo, com os Outros e com os fenômenos relacionados a nossa sensibilidade, na maior parte das vezes, inapreensíveis.

Para Gadamer (2008), o objetivo da ciência é tornar a experiência tão objetiva a ponto de anular nela qualquer elemento histórico. Essa objetividade é legitimada pelo uso de recursos metodológicos e experimentos, ou seja, procedimentos passíveis de controle, não restando espaço para a historicidade da experiência. O Movimento Humano, para Kunz (1991, p. 163), é uma forma de entendimento e compreensão do Homem em relação ao seu contexto de relações (seu Mundo). Movimento é, assim, de acordo com o autor, uma "ação em que um sujeito, pelo seu se-movimentar, se introduz no Mundo de forma dinâmica e através desta ação percebe e realiza os sentidos/significados em e para o seu meio".

$\mathrm{O}$ esporte, enquanto uma prática social e que se manifesta corporalmente, pode ser compreendido como movimento humano e linguagem, na medida em que nos distanciamos da objetividade (Objetktivität) científica como único caminho de acesso ao conhecimento, uma vez que essa tenta reduzir a complexidade do mundo à sua percepção, transformação e domínio. Segundo Almeida (2016), se nos aproximarmos da objetividade (Sachlickeit) da linguagem, que considera a dimensão de pertencimento ao mundo humano em seu caráter de historicidade, não é possível compreendê-la de fora (do mundo). Esse distanciamento nos permite pensar o esporte enquanto uma representação do movimento humano como um diálogo com o mundo, um diálogo do ser humano com sua realidade social e material.

Ao pensarmos na relação do esporte com a intencionalidade subjetiva e intersubjetiva, necessitamos compreender que a intencionalidade pedagógica da Educação Física é o movimento corporal como forma de linguagem e de estar no Mundo. Concordamos com a interpretação de Santin (1992, p. 52) que "o corpo oferece um universo ilimitado de compreensões e tratamentos. Ele pode ser visto como uma simples máquina e um mero instrumento, ou como uma obra de arte e de beleza". Neste viés, um dos desafios da relação pedagógica do esporte com a experiência estética é a reflexão do corpo como um "organismo vivo a ser desenvolvido, vivido, cultuado com equilíbrio e harmonia (SANTIN, 1992, p. 52).

Conforme Marasca (2008), foi com Kant que a Estética se consolidou como uma modalidade autônoma da experiência humana. Nessa perspectiva, a estética, como uma experiência humana, está intimamente ligada à 
subjetividade humana, que se define, no limite, pelo prazer que proporciona, pelas sensações ou pelos sentimentos que produz em nós.

Gadamer (2008, p. 519), sinaliza que "às vezes a linguagem parece pouco capaz de expressar o que sentimos", referindo-se à dificuldade de traduzir em palavras o que nos diz, e, por exemplo, ao contemplarmos uma obra de arte, um filme, uma música. Nessa perspectiva, entende-se que a prática do esporte, nas suas diversas possibilidades, constitui-se como uma experiência estética, pois faltariam "palavras" para expressar o sentido, o significado, as sensações e as percepções do sujeito que está imerso visceralmente numa prática esportiva.

\section{Esporte, movimento humano, experiência}

As práticas esportivas lúdicas e corporais sempre foram ao longo da história humana, e continuam a ser promotoras de um caráter multifuncional. Podem ser objeto de instrumentalização de muitas funções, objetivos, metas muito distintas e, até, não raras vezes, contraditórias.

Abordar o tema esporte na Educação Física exige uma opção pedagógica, pois, enquanto fenômeno, pode ser tratado a partir de diferentes vieses teóricos. A discussão aqui exposta visa a compreensão do esporte enquanto experiência estética a partir de três dimensões: a primeira relacionada às "experiências do nosso corpo" inteiramente distintas nas diferentes modalidades desportivas, assim como nas diversas formas de rendimento, de carga e exigência do desporto; a segunda às "experiências materiais" - ligadas à vivência material das coisas, dos objetos, do envolvimento e da natureza; a terceira às "experiências sociais" - adquiridas na variedade de papéis e situações da aprendizagem, do treino, do jogo e da competição.

A relação do esporte, movimento humano e experiência, ultrapassa os elementos da racionalidade em uma perspectiva instrumental. Pensar o esporte na perspectiva da experiência estética, tomando o movimento humano e o sujeito como centralidade, é pensar na configuração da formação de sentimentos de alegria, de prazer, de felicidade no rendimento, e refletir sobre as dimensões motoras, estéticas, sociais, morais, cognitivas e afetivas.

Nessa direção, na interpretação de Bracht (2012), a experiência estética é uma possibilidade de ampliar nossa compreensão sobre nós mesmos e sobre o mundo, e aprimorar nossa capacidade de escolha. Para o autor, o grande desafio em pensar a relação movimento humano e experiência estética, especialmente no espaço escolar, é que a mesma exige uma sistematização das experiências, que pode contradizer ou se contrapor à imprevisibilidade e fruição das experiências estéticas. Considerando-se que a experiência do movimentar-se não é traduzível, pois, somente pode ser vivida e experienciada de forma única, é possível, então, servir de conteúdo para o diálogo pedagógico? 
Em relação a essa questão, Bracht (2012) nos convoca a uma reflexão coletiva para enfrentá-la. Para o autor, há algumas dificuldades para transpor a teoria estética de Gadamer (2008) para concebermos uma experiência estética do movimentar-se, tendo em vista que "a teoria estética trata mais da nossa relação com uma obra que já está, e no movimentar-se trata-se da experiência em ato que se esvai nela mesma e não produz obra" (BRACHT, 2012, p. 35).

Para o enfrentamento da questão destacada por Bracht, sobre a relação experiência estética e a sistematização das experiências, optamos pela concepção dialógica para pensar o movimento humano. Esta concepção é compreendida por Kunz (1991, p. 174), do ponto de vista antropológico, como "um diálogo entre o Homem e Mundo. O Se-Movimentar do Homem é sempre um diálogo com o Mundo".

Segundo Kunz (1991, p. 174), o Se-movimentar é entendido como "diálogo entre Homem e Mundo; é um sujeito que se movimenta com sua intencionalidade; é um sujeito relacional com o Mundo e com os outros". É por meio desta intencionalidade que se constitui o sentido/significado do se-movimentar, estabelecendo-se uma relação estreita na concepção dialógica do movimento; portanto o movimento humano é intencionalidade.

Para vislumbrar uma possibilidade que nos auxilie a pensar a relação Esporte, Experiência e Movimento Humano para a Educação Física, refletindo no ensino do conteúdo esporte e sua articulação com a experiência estética, elegemos a abordagem crítico-emancipatória desenvolvida por Kunz (2001). Esta abordagem reconhece o Movimento Humano como um ensejo de penetrar num mundo desconhecido, enquanto um diálogo entre o Homem e o Mundo, por meio do desenvolvimento de competências, como a autonomia, a competência social e a competência objetiva.

A concepção crítico-emancipatória (Kunz, 2001) foi pensada como uma proposta didático-pedagógica para o ensino dos esportes. Para tanto, ela apresenta uma estrutura pedagógica que orienta o processo de intervenção que iremos expor a seguir, e que, de certa forma, contempla a nossa tese neste artigo, que é a relação de se pensar o ensino do conteúdo esporte na Educação Física, tomando a experiência estética como um conhecimento. Isso não significa que estamos negando a dimensão conceitual, mas que pensamos que a experiência estética é uma possibilidade de fomentar saberes produzidos por ela, com os elementos da cultura corporal de movimento.

A primeira proposição que Kunz (1991, p. 164) faz, refere-se à compreensão do ensino dos esportes e que deve ser superada, colocando-nos a seguinte pergunta: Em que medida o conteúdo esporte pode se traduzir numa experiência estética? Uma vez que hegemonicamente o ensino dos esportes estão centrados no paradigma da racionalidade instrumental, isso significa, segundo Trebels (1983 apud Kunz, 1991, p. 164), que os "gestos esportivos se orientam por uma interpretação técnica".

Na concepção de Kunz (1991, p. 165), a Educação Física tem sido uma tentativa de copiar, de forma irrefletida, o esporte competitivo e normatizado. $\mathrm{O}$ autor entende que a Educação Física escolar se constitui como um espaço social para potencializar os sentidos e significados dos sujeitos por meio do Movimento Humano e, para tanto, nos apresenta cinco entendimentos de Sentidos/significados do Movimento Humano: Sentido Comparativo; 
Sentido Explorativo; Sentido Produtivo; Sentido Comunicativo; Sentido Expressivo. Essas possibilidades do Movimento Humano corroboram que o Movimento em Si, como fenômeno físico, não responde tudo do que é do Humano, portanto, devemos compreender as proposições do Movimento Humano na Educação Física na perspectiva de potencializar os sentidos e significados.

A tarefa da concepção crítico-emancipatória, portanto, apresentada por Kunz (2001, p. 123), para o tratamento do ensino dos conteúdos dos esportes, está estruturada a partir de estratégias didáticas, denominados pelo autor de "transcendência de limites", em que o sujeito é confrontado com a realidade do ensino e seu conteúdo, em especial, a partir de três graus de dificuldades. Essa forma de abordar o esporte passa pelos seguintes passos:

$\left.1^{\circ}\right)$ a forma direta de "transcender limites", no sentido da manipulação direta da realidade pelo simples explorar e experimentar possibilidades e propriedades dos objetos, bem como as próprias possibilidades e capacidades e, ainda, vivenciar predisposições comunicativas, descobrir e experimentar relações socioemocionais novas, entre outras;

$2^{\circ}$ ) a forma aprendida no âmbito das possibilidades de transcender limites pela imagem, pelo esquematismo, pela apresentação verbal de situações do movimento e do jogo e que o aluno reflexivamente deverá acompanhar, executar e propor soluções; tem como base uma intencionalidade que se forma pela ideia ou imagem do movimento;

$3^{\circ}$ ) a forma criativa ou inventiva de uma "transcendência de limites", em que, a partir das duas formas anteriores da representação de um saber, o aluno se torna capaz de, "definida uma situação", criar/inventar movimentos e jogos com sentido para aquela situação, tem como base uma intencionalidade criativa, inventiva.

Conceber um ensino dos esportes centrado nessas três etapas da "transcendência de limites" desenvolve elementos reflexivos para a compreensão do esporte como uma forma de experiência estética. Com efeito, este tipo de abordagem pedagógica potencializa as seguintes dimensões: $1^{\mathrm{a}}$ ) que os alunos descubram, pela própria experiência manipulativa, as formas e os meios para uma participação bem- sucedida nos esportes, jogos, entre outros; $2^{\mathrm{a}}$ ) que os alunos sejam capazes de manifestar, pela linguagem ou pela representação cênica, o que experimentaram e o que aprenderam, numa forma de exposição pela qual todos possam entender; $3^{\mathrm{a}}$ ) por último, que os alunos aprendam a perguntar e questionar sobre suas aprendizagens e descobertas, com a finalidade de entender o significado cultural dessa aprendizagem, seu valor prático e descobrir, também, o que ainda não sabem ou aprenderam.

\section{Considerações finais}

Entendemos que o debate e a reflexão da relação esporte, experiência e conhecimento não estão esgotados, tampouco temos a pretensão de ter alcançado uma formulação definitiva para a referida temática exposta, pois 
sabemos que a finitude do conhecimento é a sua provisoriedade. Nessa perspectiva, conceber o ensino dos esportes na Educação Física escolar é tomá-lo como experiência e conhecimento, o que pode ser compreendido a partir de um palco, em que entra em cena a representação do movimento humano, das suas possibilidades, dos limites e do diálogo e relação com a nossa natureza interior e exterior, com a vida e o mundo, potencializando a formação humana.

Destacamos que a relação experiência e conhecimento não exclui um conhecimento prévio conceitual de uma determinada prática corporal, mas que o ato da experiência estética (individual e subjetiva) produz um conhecimento "visceral" no sujeito. Nesta perspectiva, os conhecimentos conceituais e corporais manifestam-se em diferentes formas de linguagem e não podem ser substituídos ou sobrepostos, pois se complementam de maneira dialógica.

Passar por uma experiência do Movimento Humano não significa necessariamente adquirir conhecimento conceitual, mas a experiência do Movimento Humano marca o sujeito, mudando-o de tal modo que ele nunca mais pode recuperar a "inocência" que perdeu com a experiência. A ciência e o conhecimento conceitual andam a par; a experiência e o Movimento Humano caminham a par. Isto não significa que rejeitamos o conhecimento conceitual, mas que temos que observar de maneira dialógica o conhecimento da área, compreendendo e refletindo a complexidade dos elementos pertencentes ao fazer pedagógico da experiência do movimento corporal para além de sua perspectiva instrumental.

Nesse sentido, a experiência do Movimento Humano é uma abertura, é um evento sempre novo, sempre diferente, não se reproduz, se produz. A experiência é antecedente ao conhecimento científico. Como experiência de um evento, o Movimento Humano é o encontro do ser com a dimensão estética, com o inapreensível, com a sua sensibilidade.

A experiência do Movimento Humano expressa um momento estético ímpar e singular; é uma possibilidade de o ser se manifestar; o momento estético não pode ser entendido separadamente de um encontro interpretativo total. A experiência do Movimento Humano tem a tarefa da interpretação, e isso significa libertar-se da objetividade científica, é recuperar o sentido da historicidade da existência.

No que diz respeito à Educação Física, concordamos com Bracht (2012), quando este destaca que é necessário que processos pedagógicos tenha a preocupação com a dimensão das experiências estéticas, mas sem abandonar e ampliar o conhecimento conceitual, até porque, para compreender o vivido, é necessário a análise e a reflexão.

\section{Referências}

ALMEIDA, Luciano. Linguagem e experiência: pensando a Educação Física na escola republicana. 2016. Tese (Doutorado em Educação). Programa de Pós-Graduação em Educação nas Ciências, Universidade Regional do Noroeste do Estado do Rio Grande do Sul - Unijuí, Ijuí, 2016. 
BAUMAN, Zygmunt. Modernidade líquida. Rio de Janeiro: Zahar, 2001.

BAUMAN, Zygmunt. Vida líquida. Rio de Janeiro: Zahar, 2007.

BRACHT, Valter. Educação Física e Ciência: cenas de um casamento (in) feliz. Ijuí: Unijuí, 2003.

BRACHT, Valter. Corpo, movimento, conhecimento, educação e Educação Física: uma exploração filosófica. Relatório de Estágio (Pós-Doutorado em Educação). Programa de Pós-Graduação em Educação, Florianópolis, UFSC, 2012.

DAMATTA, Roberto (org). Universo do futebol: esporte e sociedade brasileira. Rio de Janeiro: Pinakotheke, 1982.

GADAMER, Hans-Georg. Verdade e método I: traços fundamentais de uma hermenêutica filosófica. Petrópolis: Vozes, 2008.

KUNZ, Elenor. Educação Física \& ensino e mudanças. Ijuí: Unijuí, 1991.

KUNZ, Elenor. Transformação didático-pedagógica do esporte. 4. ed. Ijuí: Unijuí, 2001.

MARASCA, Maristela. Estética (verbete). In: GONZÁLEZ, Fernando Jaime; FESNTERSEIFER, Paulo Evaldo. Dicionário crítico. 2.ed. Ijuí: Unijuí, 2008. p.177-179.

MERLEAU-PONTY, Maurice. Textos selecionados. Tradução Marilena de Souza Chaú e, Pedro de Souza Moraes. São Paulo: Nova Cultural, 1989.

SANTIN, Silvino. Educação Física: temas pedagógicos. Porto Alegre: EST/ESEF, 1992.

SILVA, Sidinei Pithan da Silva. Pós-modernidade, capitalismo e educação: a universidade na crise do projeto social moderno. Curitiba: Appris, 2016.

Como citar este artigo

CARLAN, Paulo; DÜRKS, Daniel Bardini. Esporte, experiência e conhecimento: um diálogo possível na educação física. Revista Kinesis, Santa Maria, v. 37, p. 01-11, 2019. 